\title{
Producción de proteínas recombinantes a partir de animales transgénicos: Sistemas y aplicaciones
}

\section{Recombinant protein production from transgenic animals: Systems and applications}

\author{
María Fernanda Alvarado-Madrigal', Tannia Chavarría-Quirós², \\ Brayan Leiva-Montero ${ }^{3}$, Juan José Mora-Román ${ }^{4}$
}

Fecha de recepción: 22 de enero de 2019 Fecha de aceptación: 1 de mayo de 2019

Alvarado-Madrigal, M; Chavarría-Quirós, T; Leiva-Montero, B; Mora-Román, JJ. Producción de proteínas recombinantes a partir de animales transgénicos: Sistemas y aplicaciones. Tecnología en Marcha. Vol. 32-4. Octubre-Diciembre 2019. Pág 133-144.

doi) https://doi.org/10.18845/tm.v32i4.4798

1 Estudiante de Licenciatura en Farmacia, Facultad de Farmacia, Universidad de Costa Rica, San José, Costa Rica. Correo electrónico: maria.alvaradomadrigal@ucr.ac.cr. (iD) https://orcid.org/0000-0002-7472-4226

2 Estudiante de Licenciatura en Farmacia, Facultad de Farmacia, Universidad de Costa Rica, San José, Costa Rica. Correo electrónico: tannia.chavarria@ucr.ac.cr. (iD) https://orcid.org/0000-0002-0381-7599

3 Estudiante de Licenciatura en Farmacia, Facultad de Farmacia, Universidad de Costa Rica, San José, Costa Rica. Correo electrónico: brayan.leiva@ucr.ac.cr. (iD https://orcid.org/0000-0002-3003-5269

4 Máster en Bioquímica, Departamento de Farmacia Industrial, Facultad de Farmacia, Universidad de Costa Rica, San José, Costa Rica. Correo electrónico: juanjose.moraroman@ucr.ac.cr. 


\title{
Palabras clave
}

Biotecnología; Ingeniería Genética; animales transgénicos; proteínas recombinantes.

\section{Resumen}

El uso de animales transgénicos para la producción de proteínas recombinantes con fines terapéuticos ha sido una alternativa utilizada para la producción de medicamentos. La habilidad de realizar complejas modificaciones post traduccionales de una manera eficiente es una ventaja que este tipo de tecnología posee sobre el uso de otros organismos transgénicos. Por esta razón, a lo largo de los años se han desarrollado diferentes animales transgénicos (rumiantes, conejos, cerdos, aves e insectos) y se han estudiado distintos sistemas (leche, huevo, sangre, orina y fluido seminal) para la obtención de proteínas recombinantes. Cada animal y cada sistema cuenta con ventajas y desventajas, las cuales deben ser consideradas antes de comenzar el proceso productivo de la proteína de interés. Medicamentos como el ATryn $\AA$, el Ruconest $\circledast$ y el Kanuma ${ }^{\circledR}$ ya han sido aprobados por la FDA para la administración en humanos. El futuro de este tipo de preparados debe ser tomado en consideración, pues existen varias proteínas terapéuticas que se hallan en fase de investigación o a la espera de ser aprobadas y comercializadas.

\section{Keywords}

Biotechnology; Genetic Engineering; transgenic animals; recombinant proteins.

\begin{abstract}
The use of transgenic animals for the production of recombinant proteins for therapeutic purposes has been an alternative used for the production of drugs. The ability to make complex post-translational modifications in an efficient manner is an advantage that this type of technology has over the use of other transgenic organisms. For this reason, different transgenic animals (ruminants, rabbits, pigs, birds and insects) have been developed over the years and different systems (milk, egg, blood, urine and seminal fluid) have been studied to obtain recombinant proteins. Each animal and each system has advantages and disadvantages, which should be considered before starting the productive process of the protein of interest. Drugs such as ATryn $®$, Ruconest $\circledast$ and Kanuma $\circledR$ have already been approved by the FDA for human administration. The future of this type of preparations must be considered, given that there are several therapeutic proteins that are in the research phase or waiting to be approved and commercialized.
\end{abstract}

\section{Introducción}

La Biotecnología se define como el uso de organismos vivos en una materia prima dada con el propósito de obtener un producto en particular [1]. Previo a la implementación de la técnica de ADN recombinante para la producción de proteínas con fines terapéuticos, estas eran obtenidas por medios menos seguros, como es el caso del aislamiento de insulina del páncreas de cerdos o como la hormona del crecimiento, que se obtenía de cadáveres de personas. Esto representaba un reto, ya que con estos métodos existía un gran riesgo de contraer alguna enfermedad, debido a las inadecuadas técnicas de purificación con las que se contaba en esa época [2]. Debido a esto, la tecnología del ADN recombinante significó una gran revolución, pues aumentó la seguridad del proceso gracias a novedosas técnicas de purificación y se incrementó la cantidad de proteínas obtenidas [3]. 
Desde la comercialización del primer fármaco obtenido mediante dicha tecnología (insulina basal de efecto prolongado) en 1982 [2], la Biotecnología ha producido un gran impacto sobre la vida de las personas y sobre la Salud Pública. Además, el desarrollo de procesos a escala industrial ha representado un gran ingreso a las compañías farmacéuticas. Se estima que en el 2013 se obtuvieron ganancias por más de 175000 millones de dólares por la venta de productos recombinantes [4]. Una de las razones de este gran auge está ligada a la variedad de disciplinas que abarca la Biotecnología, tales como Bioinformática, Ingeniería, Nanotecnología, Biología Molecular, Bioquímica, entre otras [5]. Este carácter interdisciplinario ha permitido el desarrollo de distintas estrategias de manufactura, una de las cuales es el uso de animales como biorreactores para la producción de proteínas recombinantes. A pesar de ser un proceso complicado, permite obtener grandes cantidades del producto de interés a un menor costo, en comparación a los procesos que utilizan células eucariotas aisladas [6]. Lo anterior ha promovido que distintos laboratorios de investigación y compañías farmacéuticas se centren en el perfeccionamiento y en la producción de nuevos productos biotecnológicos que lleguen a suplir una necesidad para mejorar la salud de la población.

El objetivo de la presente revisión es proporcionar información sobre la producción de proteínas recombinantes a partir de animales transgénicos y su aplicabilidad para la elaboración de productos biotecnológicos por parte de la industria farmacéutica.

\section{Técnicas de ADN recombinante para la producción de proteínas}

La implementación de la tecnología del ADN recombinante es uno de los grandes avances en el área de la Biotecnología. La misma permite transferir genes de una especie en el genoma de otra especie, con la finalidad de utilizar la maquinaria metabólica de esta última para producir una proteína que no sintetizaría de forma natural. Previo al desarrollo de esta metodología, los seres humanos ya utilizaban microorganismos, con la finalidad de obtener alimentos como pan y vino. Tales prácticas fueron estudiadas por Louis Pasteur, quien descubrió el papel esencial que poseían algunos de ellos sobre los procesos de fermentación [7]. A partir de estos conocimientos, se dio el auge de la industria de bioproducción de alimentos, la cual sigue siendo muy importante en la actualidad.

Durante la década de 1960, sucedió un progreso científico, debido a la elucidación de la estructura y de los mecanismos de la replicación, la expresión y la regulación de genes procariotas. Tal situación sentó las bases para el desarrollo de investigaciones para descubrir dichos procesos en células eucariotas [8]. Gracias a los hallazgos encontrados durante las mismas, en 1972 Berg, Cohen y Boyer introdujeron la tecnología del ADN recombinante, al construir el primer plásmido recombinante, introducido exitosamente en una bacteria. Esto sirvió como base para que años después se diera la expresión de la primera proteína humana en Escherichia coli [2]. En 1982, la Administración de Alimentos y Medicamentos (FDA, por sus siglas en inglés) aprobó el uso del primer fármaco producido por medio de la tecnología del ADN recombinante, utilizando esta bacteria. Dicho fármaco fue denominado Humulin $\circledast$, el cual es una insulina basal de efecto prolongado/intermedio [9].

Para el proceso de producción de proteínas recombinantes es necesario utilizar enzimas de restricción. Estas son enzimas cortadoras de ADN, es decir, son capaces de cortar el enlace fosfodiéster que une los nucleótidos adyacentes de este material genético. Dicho reconocimiento lo realizan a través de la ubicación de secuencias específicas de nucleótidos, usualmente cuatro a ocho pares de bases [10]. Su descubrimiento y su empleo han permitido elaborar mapas de plásmidos y del genoma de cada uno VEGF165 de los vectores utilizados para la producción de ADN recombinante, lo cual es esencial para conocer que segmentos del plásmido se pueden cortar para insertar el gen foráneo [11]. 
Otraherramienta esencial de esta tecnología son los plásmidos. Setrata de ADN extracromosómico capaz de codificar para proteínas que le brindan distintas funciones a la bacteria, como resistencia a los antibióticos, degradación de toxinas presentes en el medio, producción de proteínas que facilitan el proceso de replicación celular, entre otras [12]. La utilidad de los plásmidos es su capacidad para aceptar genes. Esto es una ventaja para la producción de ADN recombinante.

El éxito del proceso de inserción de los genes en el plásmido puede ser comprobado al añadir genes de resistencia hacia un antibiótico. Si con el tiempo se observa el desarrollo de resistencia hacia este, el proceso de inserción del material genético en la bacteria fue exitoso [13]. No obstante, esta técnica está en desuso debido a la problemática que representa la resistencia a los antibióticos hacia la Salud Pública. Por ello, se han desarrollo otras estrategias como la presencia de un sitio de restricción en el gen lacZ. Este gen es interrumpido por la inserción del ADN recombinante, ocasionando la disminución de la expresión de $\beta$-galactoxidasa funcional. Para verificar esta situación, se añaden los sustratos de esta enzima y el inductor isopropil- $\beta$-D1-tiogalactopiranósido (IPTG), el cual posee la función de promover la expresión de la enzima. Si la inserción fue exitosa, las colonias se presentan de color blanco. En contraposición, si la inserción no sucedió u ocurrió en una zona distinta a la del gen lacZ, las colonias se aprecian de color azul, como consecuencia de los productos derivados de la reacción en presencia de la enzima funcional [14].

Gracias a distintos estudios, se ha encontrado que es posible emplear esta técnica para insertar genes en modelos animales. En uno de ellos, con la ayuda del plásmido VEGF165, se ha logrado transferir el gen que codifica para el factor de crecimiento endotelial vascular (VEGF, por sus siglas en inglés) en ratas Fisher, favoreciendo el proceso de angiogénesis. Esto es de utilidad en distintas patologías como enfermedades cardiacas isquémicas e isquemia en las extremidades inferiores [15]. Además, esta técnica posee aplicabilidad en modelos animales de mayor tamaño. Con la inyección de una solución con hidrogel de alginato, plásmidos que contenían el gen que codifica para la proteína morfogenética ósea 2 (BMP-2, por sus siglas en inglés) y células estromales multipotentes de cabra, ha sido posible aumentar la formación de nuevas estructuras óseas en cabras [16].

Además de la clonación por medio de plásmidos, se usan bacteriófagos como el lambda $(\lambda)$. En esta técnica, se inserta el ADN clonado dentro de los sitios de restricción en el centro del cromosoma $\lambda$. Dichos cromosomas recombinantes se insertan dentro de los fagos, los cuales infectan a la bacteria. Con ello, se lleva a cabo la inserción de varios genes, al ser posible cortar diversas partes del ADN viral. Además, como los bacteriófagos poseen mecanismos propios para insertar el material genético dentro de las bacterias, se produce ADN recombinante con una mayor tasa de éxito [17] [18].

Los bacteriófagos también son ampliamente utilizados en modelos animales. Por ejemplo, gracias al bacteriófago IME-SA1 se ha logrado obtener endolisina activa recombinante en especies bovinas, efectiva para el tratamiento de mastitis bovina producida por cepas de Staphylococcus aureus meticilino resistentes (MRSA, por sus siglas en inglés) [19]. También se pueden emplear en animales más pequeños como los conejos para el tratamiento de osteomielitis crónica causada por MRSA [20]. Por todo esto, los plásmidos y los bacteriófagos son herramientas biotecnológicas de gran utilidad para la producción de proteínas recombinantes en animales transgénicos. 


\section{Sistemas y animales transgénicos para la producción de proteínas recombinantes de uso terapéutico}

El uso de mamíferos como biorreactores en la industria biotecnológica permite la síntesis de proteínas que no pueden obtenerse a partir de otros organismos menos complejos. Esto se debe a que cuentan con la maquinaria enzimática necesaria para realizar diferentes modificaciones post traduccionales. La glicosilación de proteínas es una de ellas. Se trata de una modificación, ya sea en los grupos hidroxilo de los residuos de serina y de treonina (O-glicosilación) o en los grupos funcionales de las cadenas laterales de los residuos de asparagina ( $\mathrm{N}$-glicosilación). Otras modificaciones importantes de este tipo en mamíferos son la carboxilación de factores de coagulación en los residuos de ácido $\gamma$-carboxiglutámico, la adición de un residuo de sulfato en el grupo $\mathrm{OH}$ de la tirosina y la adición de grupos fosfato a cadenas laterales de aminoácidos (fosforilación) [21].

Asimismo, el uso de otros sistemas como bacterias puede llevar a la obtención de proteínas con propiedades no deseadas, incluyendo una alta inmunogenicidad y una falta de actividad, pues, como se mencionó anteriormente, no sufren modificaciones post traduccionales, necesarias para que sean funcionales para los seres humanos. Por otro lado, el uso de levaduras sí permite obtener ciertas modificaciones en las proteínas recién sintetizadas, pero son diferentes a aquellas que toman lugar en células de mamífero [22]. Adicionalmente, esos sistemas de expresión no pueden asegurar un adecuado plegamiento de las proteínas recombinantes [23] [24]. Por todo lo anterior, los animales transgénicos ofrecen oportunidades atractivas para la síntesis de proteínas con potencial terapéutico.

Dentro de las principales ventajas del uso de animales transgénicos están la posible disminución en los costos de producción (el costo de producción de una plataforma animal está estimada en una décima parte del costo de la construcción de un biorreactor para células [25]) y un aumento en la calidad de las proteínas, por todas las funciones capaces de realizar dichos animales a nivel genético [26].

Sin embargo, un inconveniente de este tipo de sistemas está en la dificultad de separar las proteínas humanas de la contraparte animal. Además, debe asegurarse que los patógenos animales no estén presentes en los preparados proteicos y que las proteínas recombinantes no sean activas o nocivas para los animales transgénicos [26].

\section{Sistemas transgénicos utilizados para la obtención de proteínas recombinantes}

\section{Leche}

La glándula mamaria ha sido considerada el tejido de elección para expresar proteínas recombinantes de gran valor en animales transgénicos, porque la leche es recolectada en grandes volúmenes en animales rumiantes [27] [28]. Como complemento, la glándula es capaz de realizar modificaciones post traduccionales y patrones de glicosilación similares a las humanas [29]. Por ello, este sistema suele utilizarse en cabras, ovejas y vacas [30].

En cuanto al producto de dicho tejido (la leche), ofrece la ventaja de que las proteínas recombinantes puedan estar almacenadas sin ningún tipo de alteración a la salud del animal, problema presentado cuando se utilizan otros sistemas como la sangre. Una excepción a la afirmación anterior está en la producción de eritropoyetina en leche de conejo. Esta provoca un aumento anormal en la cantidad de eritrocitos, impidiendo la reproducción exitosa de los animales, así como la obtención de leche de ellos, y ocasionando su muerte prematura [31]. 
También se ha reportado que otra ventaja de este sistema se relaciona con la cantidad de proteínas recombinantes obtenidas. Se indica la posibilidad de conseguir varios gramos por litro de leche producida [32] [33].

Sin embargo, la producción de proteínas en la leche se ve limitada debido al intervalo relativamente largo entre el nacimiento y la lactancia de los mamíferos rumiantes, la naturaleza discontinua en el ciclo de lactancia, y la cantidad de tiempo y de dinero invertidos en la manutención de estos animales [34]. Otro factor limitante es la dificultad en el posterior aislamiento de la proteína recombinante como consecuencia de la presencia de micelas de caseína y grasa en la leche. Esto implica la adición de procesos adicionales para la separación y la purificación de la proteína. Algunas de ellas son la centrifugación de los glóbulos de grasa seguida por la filtración en membrana de las micelas, los métodos de intercambio iónico, la separación de la caseína mediante el uso de ácido etilendiaminotetraacético (AEDT) y fosfato de calcio, la disminución de pH y la precipitación con polietilenglicol. Una desventaja que conlleva la separación de la caseína por precipitación usando dichas técnicas es la potencial pérdida de la proteína deseada, que puede quedar ocluida en el precipitado de caseína [35] [36] [37].

\section{Clara de huevo}

Recientemente se ha empezado a utilizar la clara de huevo para la obtención de proteínas recombinantes, debido a la creación de gallinas transgénicas. Las ventajas son que una única gallina puede producir más de 330 huevos al año, su producción se da en cortos períodos y la clara de huevo contiene cerca de cuatro gramos de proteína [38] [39].

\section{Sangre}

Este sistema ha sido considerado para aislar proteínas circulantes en sangre. No obstante, es poco ideal, debido a que el proceso de obtención es muy invasivo para el animal [40]. Junto con ello, el aislamiento de las proteínas humanas de las del animal puede tener cierta dificultad, especialmente cuando se deben separar a partir de sangre de cerdo, la cual posee proteínas con afinidades muy similares a su contraparte humana, dificultando la purificación mediante cromatografía de intercambio iónico [41] [42]. Además, las proteínas circulantes podrían afectar la vida del animal hasta hacerlo impráctico. Se ha demostrado que en cerdos transgénicos la sobreexpresión de la hormona de crecimiento produce un detrimento en su salud general, ocasionando letargo, úlceras gástricas, cojera y pérdida del libido [27] [43].

\section{Orina}

Distintas investigaciones han explorado la posibilidad de utilizar la vejiga como un biorreactor, al modificar las células que la revisten, y promover la producción y la secreción de proteínas a la orina [44] [45] [46] [47]. La ventaja de este sistema sobre la leche es que la producción de orina se da mucho más rápida, el proceso de purificación es más simple y se obtienen proteínas análogas a las humanas [40]. Asimismo, los efectos de las proteínas recombinantes son menos dañinos para la salud del animal en comparación con los de aquellas que se obtienen de la sangre [48]. El factor limitante es que la tasa de producción de proteínas es muy baja [40].

\section{Fluido seminal}

El fluido seminal se consideró para la secreción de proteínas recombinantes en animales transgénicos, ya que se ha podido recuperar hasta $30 \mathrm{mg}$ de proteína por $\mathrm{mL}$ de líquido seminal porcino. En cuando al semen de jabalí, en 200 a $300 \mathrm{~mL}$ de este se recuperaron de seis a nueve gramos de proteína. Otra ventaja consiste en la automatización a gran escala de la recolección de semen de cerdos y jabalíes en unidades de inseminación artificial. Junto con 
ello, la excreción de proteínas por este medio es meramente exocrino, minimizando el riesgo de que los productos recombinante puedan causar algún daño en la salud del animal [27]. Pero, una de las limitantes es que no se sabe aún el efecto que dicha expresión tiene sobre la fertilidad del animal y, consecuentemente, la posible afectación de la continuidad de la línea transgénica [49].

\section{Animales transgénicos para la producción de proteínas recombinantes}

Rumiantes

Son potencialmente la especie más apropiada para producir grandes cantidades de proteínas en leche. Las cabras transgénicas, por ejemplo, tienen una producción de leche promedio de entre 600 y 800 litros por animal en cada período de lactancia y se adaptan bien para la obtención de proteínas terapéuticas. El tiempo que transcurre desde la transferencia génica hasta la producción de leche es de 16 a 18 meses y se pueden llegar a obtener varios cientos de kilogramos de producto al año. Por su parte, las vacas lecheras pueden llegar a producir hasta 10000 litros de leche al año. Por tanto, se pueden conseguir rendimientos en la producción de proteínas terapéuticas de decenas de kilogramos por vaca transgénica. A pesar de eso, toma más de tres años desde la transferencia del material genético hasta la obtención de la leche con los productos de interés [29].

En cuanto a las ovejas transgénicas, pueden llegar a producir hasta 300 litros de leche al año por oveja, su ciclo de lactancia es de 14 meses y se han obtenido rendimientos de hasta 35 $\mathrm{g} / \mathrm{L}$ de proteínas recombinantes en su leche. La desventaja es que toma cerca de dos años el llegar a un nivel de producción adecuado después de la transferencia génica [24] [50] [51].

Otros aspectos a considerar con respecto a los rumiantes transgénicos son la necesidad de clonación para ser obtenidos o el uso de vectores lentivirales para la integración de genes ajenos, una reproducción relativamente lenta, la inadecuada glicosilación de las proteínas con respecto a los conejos y a los cerdos, y su sensibilidad a enfermedades ocasionadas por priones [26].

\section{Conejos}

Estos mamíferos heredan las modificaciones genéticas fácilmente a la descendencia, poseen una alta fertilidad, una producción de leche relativamente alta, insensibilidad a enfermedades por priones y no generan la transmisión de enfermedades severas a humanos. Asimismo, respecto a los rumiantes, poseen un intervalo de gestación corto, permitiéndoles tener hasta ocho períodos de lactancia al año. Aún así, sólo es posible recuperar 1,5 litros de leche por período de lactancia. Tal situación limita su valor como sistema de expresión a nivel industrial, ya que para obtener cantidades sustanciales de leche, sigue siendo necesaria una considerable cantidad de animales [26] [29].

\section{Cerdos}

El uso de cerdos en la producción de proteínas recombinantes tiene como punto negativo su costo [26]. Los cerdos hembra, en lactancia, pueden llegar a producir de 100 a 200 litros de leche y se ha reportado que las células de la glándula mamaria porcina puede llevar a cabo complejas modificaciones post traduccionales como $\gamma$-carboxilación, como se mencionó anteriormente [52].

Estos animales también han sido considerados para la recuperación de proteínas recombinantes de su fluido seminal. Las glándulas sexuales porcinas poseen una capacidad elevada para 
la obtención de dichas sustancias, una producción continua de estas a través de toda la vida reproductiva del animal y la habilidad de producir modificaciones post traduccionales complejas [27].

\section{Aves en las claras de huevo [27]. \\ Insectos \\ Aplicaciones de los sistemas y animales para la obtención de proteínas recombinantes con usos terapéuticos}

El uso de gallinas transgénicas como biorreactores puede ser de utilidad dado su alto nivel de producción de proteínas recombinantes. Ha sido posible la creación de estas mediante el uso de vectores lentivirales y células germinales. Las células con genes foráneos son introducidas en embriones, produciéndose gallinas quiméricas capaces de secretar anticuerpos monoclonales

En muchos hay un rápido período de crecimiento larval, lo cual involucra una gran síntesis de proteínas antes de la pupación. Algunos insectos transgénicos han representado sistemas económicamente ventajosos para producir estas sustancias, debido a su corto tiempo de reproducción, la tecnología disponible para su producción en masa y la habilidad de ejecutar complejas modificaciones post traduccionales [53] [54]. Otra ventaja demostrada es que los genes insertados en su genoma pueden heredarse hasta 50 generaciones, haciendo viable la producción a gran escala de proteínas recombinantes obtenidas a partir de su hemolinfa [55].

El desarrollo de animales genéticamente modificados para producir proteínas recombinantes con actividad terapéutica ha estado en curso por más de 30 años. Sin embargo, hasta el 2009 la FDA aprobó el primer medicamento de este tipo, registrado con el nombre de ATryn® [56]. Esta es una forma recombinante de la antitrombina humana producida en cabras [29]. La misma previene la formación de coágulos en pacientes que no poseen la proteína de forma endógena. Está indicado para deficiencia hereditaria de antitrombina, enfermedad que afecta a una en 3000 a 5000 personas [3].

Para el 2018, únicamente otras dos proteínas producidas a partir de animales genéticamente modificados han sido aprobadas para ser empleadas como medicamentos en humanos. Estas fueron registradas bajo los nombres comerciales Ruconest $₫$ y Kanuma $®$. Su aprobación por la FDA se llevó a cabo en el 2014 y en el 2015, respectivamente [57].

El Ruconest $₫$ o conestat alfa es un inhibidor recombinante de la C1 esterasa. Específicamente, es una glicoproteína soluble de cadena sencilla que contiene 478 aminoácidos y posee una masa molecular de $68 \mathrm{kDa}$, de los cuales aproximadamente el 22 \% comprende estructuras de oligosacáridos. Se obtiene de la leche de conejos genéticamente modificados. Es una formulación estéril, libre de preservantes, y en forma de polvo liofilizado para su reconstitución y su posterior aplicación por vía intravenosa [58].

Este producto se emplea para el tratamiento de ataques agudos en pacientes con angioedema hereditario. Se trata de un desorden autosómico recesivo hereditario en la sangre, causado por la deficiencia de la proteína inhibitoria de la C1 esterasa. Dicha deficiencia causa síntomas agudos como inflamación excesiva en la cara, extremidades, genitales, tracto gastrointestinal y vías respiratorias superiores. Sin el adecuado tratamiento, el excesivo hinchamiento de las vías respiratorias puede llegar a amenazar la vida [59]. El propósito del medicamento es restablecer el nivel del inhibidor de C1 esterasa en el plasma, con el fin de tratar ataques agudos [58]. 
En cuanto a la sebelipasa alfa (Kanuma®), es una lipasa ácida lisosomal (LAL) humana recombinante desarrollada para ser usada como terapia enzimática de reemplazo a largo plazo en pacientes con deficiencia de esta enzima. Dicha deficiencia se debe a una enfermedad autosómica recesiva poco común relacionada con el almacenamiento lisosomal. Específicamente, es producto de mutaciones en el gen LIPA (en inglés) que codifica para la enzima LAL. Su deficiencia causa la acumulación de ésteres de colesterol y triglicéridos, particularmente en hepatocitos y macrófagos [60].

Kanuma ${ }^{\circledR}$ se administra por infusión intravenosa, reduciendo la acumulación de lípidos lisosomales. De esta forma, se disminuyen ciertos problemas relacionados a su deficiencia, entre ellas dislipidemias y anormalidades hepáticas. La proteína es producida y purificada mediante claras de huevo de gallinas transgénicas [60]. Actualmente, existen otras proteínas recombinantes obtenidas de leche de animales transgénicos con posible valor terapéutico, pero no han sido aprobadas, ni comercializadas [57]. Las mismas se detallan en el cuadro 1.

Cuadro 1. Proteínas recombinantes con valor terapéutico producidas a partir de animales transgénicos que se encuentran en fase de desarrollo [29] [61] [62] [63] [64].

\begin{tabular}{|c|c|c|c|}
\hline Producto & $\begin{array}{l}\text { Animal de } \\
\text { producción }\end{array}$ & Empresa & Uso \\
\hline $\begin{array}{c}\text { Alfa-antitripsina } \\
\text { (AAT) }\end{array}$ & Cabra & rEVO Biologics & $\begin{array}{l}\text {-Terapia de reemplazo para la deficiencia de AAT } \\
\text { (trastorno genético que puede causar problemas } \\
\text { pulmonares) } \\
\text {-AAT es el principal inhibidor de proteasas en el } \\
\text { plasma humano }\end{array}$ \\
\hline $\begin{array}{c}\text { CD137 (4-1BB) } \\
\text { mAb }\end{array}$ & Cabra & rEVO Biologics & $\begin{array}{l}\text {-Tratamiento del cáncer y trastornos autoinmunes } \\
\text {-CD137 (4-1BB) es una molécula coestimuladora } \\
\text { que puede regular respuestas inmunes }\end{array}$ \\
\hline MM-093 (AFP) & Cabra & $\begin{array}{l}\text { Merrimack y } \\
\text { rEVO Biologics }\end{array}$ & $\begin{array}{l}\text {-Tratamiento de miastenia gravis, esclerosis múltiple, } \\
\text { artritis reumatoide y psoriasis } \\
\text {-Versión recombinante de la alfa-fetoproteína } \\
\text { humana, la cual tiene función inmunomoduladora }\end{array}$ \\
\hline Alfa-glucosidasa & Conejo & Pharming & $\begin{array}{l}\text {-Tratamiento de la enfermedad de Pompe (defectos } \\
\text { en el almacenamiento lisosomal), causada por } \\
\text { deficiencia de alfa-glucosidasa } \\
\text {-Enfermedad genera acumulación de glucógeno } \\
\text { dentro de los lisosomas y el citoplasma, llevando a } \\
\text { la destrucción de tejido }\end{array}$ \\
\hline
\end{tabular}

\section{Conclusiones}

Con el auge de la Biotecnología, la producción de proteínas terapéuticas a base de tecnología del ADN recombinante es uno de los métodos para la obtención de productos para el tratamiento de diversas enfermedades. Como fuente para la síntesis de proteínas (biorreactores) se cuentan con los animales transgénicos (rumiantes, conejos, cerdos, aves e insectos), cuyo genoma ha sido modificado a partir de plásmidos o bacteriófagos. Estos representan una alternativa a otros sistemas de expresión como bacterias, levaduras, hongos o células de mamífero, pues permiten la obtención de proteínas con modificaciones post traduccionales más complejas y a un costo de producción menor. Sin embargo, también muestran desventajas referentes a la purificación de los productos finales y los efectos de estos sobre la salud de los animales. 
Como complemento, los sistemas transgénicos utilizados en la obtención de proteínas recombinantes incluyen la leche, los huevos, la sangre, la orina y el fluido seminal. La leche es el sistema más comúnmente elegido. Al igual que con los animales, cada sistema cuenta con ventajas y desventajas, las cuales deben ser consideradas antes de comenzar el proceso productivo de la proteína de interés.

Medicamentos como el ATryn $®$, el Ruconest $₫$ y el Kanuma® ya han sido aprobados por la FDA paita la administración en humanos. El futuro de este tipo de preparados debe ser tomado en consideración, pues existen varias proteínas terapéuticas que se hallan en fase de investigación o a la espera de ser aprobadas y comercializadas.

\section{Referencias}

[1] H. Almeida, M. H. Amaral, and P. Lobão, "Drugs obtained by biotechnology processing," Brazilian Journal of Pharmaceutical Sciences, 47(2), 199-207, 2011.

[2] K. Buchholz and J. Collins, "The roots-a short history of industrial microbiology and biotechnology," Applied Microbiology and Biotechnology, 97(9), 3747-3762, 2013.

[3] C. Schmidt, "Belated approval of first recombinant protein from animal," Nature Biotechnology, 24(8), 877, 2006.

[4] R. Evens and K. Kaitin, "The evolution of biotecnology and its impact on health care," Health Affairs, 34(2), 210-219, 2015.

[5] N. K. Ganguly, S. Croft, L. Singh, S. Sinha, and T. Balganesh, "Biomedicine and Biotechnology: Public Health Impact," BioMed Research International, 2014, 1-2, 2014.

[6] M. V. Shepelev, S. V. Kalinichenko, A. V. Deykin, and I. V. Korobko, "Production of Recombinant Proteins in the Milk of Transgenic Animals: Current State and Prospects," Acta Naturae, 10(3), 40-47, 2018.

[7] Y. H. P. Zhang, J. Sun, and Y. Ma, "Biomanufacturing: history and perspective," Journal of Industrial Microbiology \& Biotechnology, 44(4-5), 773-784, 2017.

[8] P. Berg and J. E. Mertz, "Personal Reflections on the Origins and Emergence of Recombinant DNA Technology," Genetics, 184(1), 9-17, 2010.

[9] J. Sandow, W. Landgraf, R. Becker, and G. Seipke, "Equivalent Recombinant Human Insulin Preparations and their Place in Therapy," European Endrocrinology, 11(1): 10-16, 2015.

[10] S. E. Wirt and M. H. Porteus, "Development of nuclease-mediated site-specific genome modification," Current Opinion in Immunology, 24(5), 609-616, 2012.

[11] P. F. R. Little and S. H. Cross, "A cosmid vector that facilitates restriction enzyme mapping," Proceedings of the National Academy of Sciences of the United States of America, 82(10), 3159-3163, 1985.

[12] P. Jajesniak and T. S. Wong, "QuickStep-Cloning: a sequence-independent ligation-free method for rapid construction of recombinant plasmids," Journal of Biological Engineering, 9(15), 2015.

[13] J. Mairhofer, M. Cserjan-Puschmann, G. Striedner, K. Nöbauer, E. Razzazi-Fazeli, and R. Grabherr, "Markerfree plasmids for gene therapeutic applications-Lack of antibiotic resistance gene substantially improves the manufacturing process," Journal of Biotechnology, 146(3), 130-137, 2010.

[14] J. A. Gossen, A. C. Molijn, G. R. Douglas, and J. Vijg, "Application of galactose-sensitive E. coli strains as selective hosts for LacZ plasmids," Nucleic Acids Research, 20(12), 3254, 1992.

[15] J. Skóra, P. Barć, T. Dawiskiba, D. Baczyńska, and A. Mastalerz-Migas, "Angiogenesis after plasmid VEGF165 gene transfer in an animal model," Central European Journal of Immunology, 38(3), 305-309, 2013.

[16] F. Wegman, R. E. Geuze, Y. J. van der Helm, F. Cumhur Öner, W. J. A. Dhert, and J. Alblas, "Gene delivery of bone morphogenetic protein-2 plasmid DNA promotes bone formation in a large animal model, Journal of Tissue Engineering and Regenerative Medicine, 8(1), 763-770, 2014.

[17] C. E. Catalano, "Bacteriophage lambda: The path from biology to theranostic agent," Wiley Interdisciplinary Reviews Nanomedicine and Nabiotechnology, 10(5), e1517, 2018.

[18] E. M. Ryan, S. P. Gorman, R. F. Donnelly, and B. F. Gilmore, "Recent advances in bacteriophage therapy: how delivery routes, formulation, concentration and timing influence the success of phage therapy," Journal of Pharmacy and Pharmacology, 63(10), 1253-1264, 2011. 
[19] J. Fan, Z. Zeng, K. Mai, Y. Yang, J. Feng, Y. Bai et al, "Preliminary treatment of bovine mastitis caused by Staphylococcus aureus, with trx-SA1, recombinant endolysin of S. aureus bacteriophage IME-SA1," Veterinary Microbiology, 191, 65-71, 2016.

[20] C. Kishor, R. R. Mishra, S. K. Saraf, M. Kumar, A. K. Srivastav, and G. Nath, "Phage therapy of staphylococcal chronic osteomyelitis in experimental animal model," Indian Journal of Medical Research, 143(1), 87-94, 2016.

[21] D. G. Knorre, N. V. Kudryashova, and T. S. Godovikova, "Chemical and Functional Aspects of Posttranslational Modification of Proteins," Acta Naturae, 1(3), 29-51, 2009.

[22] O. G. Maksimenko, A. V. Deykin, Y. M. Khodarovich, and P. G. Georgiev, "Use of Transgenic Animals in Biotechnology: Prospects and Problems," Acta Naturae, 5(1), 33-46, 2013.

[23] Y. Durocher and Butler M, "Expression systems for therapeutic glycoprotein production," Current Opinion in Biotechnology, 20(6), 700-707, 2009.

[24] A. L. Demain and P. Vaishnav, "Production of recombinant proteins by microbes and higher organisms," Biotechnology Advances, 27(3), 297-306, 2009.

[25] A. Dove, "Uncorking the biomanufacturing bottleneck," Nature Biotechnology, 20(8), 777-779, 2002.

[26] L. M. Houdebine, "Production of pharmaceutical proteins by transgenic animals," Comparative Immunology, Microbiology \& Infectious Diseases, 32(2), 107-121, 2009.

[27] M. K Dyck, D. Lacroix, F. Pothier, and M. -A. Sirard, "Making recombinant proteins in animals - different systems, different applications," Trends in Biotechnology, 21(9), 394-399, 2003.

[28] Organización de las Naciones Unidas para la Alimentación y la Agricultura, "Producción y productos: Animales lecheros, 2018. Disponible en: http://www.fao.org/dairy-production-products/production/productiondairy-animals/es/ (Accesado: 9-dic-2018)

[29] Y. Echelard, C. A. Ziomek, and H. M. Meade, "Production of recombinant therapeutic proteins in the milk of transgenic animals," Biopharm International, 19(8), 36-46, 2006.

[30] W. H. Eyestone, "Production and breeding of transgenic cattle using in vitro embryo production technology," Theriogenology, 51(2), 509-517, 1999.

[31] M. Massoud, J. Attal, D. Thépot, H. Pointu, M. G. Stinnakre, M. C. Théron et al, "The deleterious effects of human erythropoietin gene driven by the rabbit when acidic protein gene promoter in transgenic rabbits", Reproduction Nutrition Development, 36(5), 555-563, 1996.

[32] L. M. Houdebine, "The production of pharmaceutical proteins from the milk of transgenic animals," Reproduction Nutrition Development, 35(6), 609-617, 1995.

[33] K. Potočnik, V. Gantner, K. Kuterovac, and A. Cividini, "Mare's milk: composition and protein fraction in comparison with different milk species," Mljekarstvo, 61(2), 107-113, 2011.

[34] R. J. Wall, D. E. Kerr, and K. R. Bondioli, "Transgenic Dairy Cattle: Genetic Engineering on a Large Scale," Journal of Dairy Science, 80(9), 2213-2224, 1997.

[35] T. D. Wilkins and W. Velander, "Isolation of recombinant proteins from milk," Journal of Cellular Biochemistry, 49(4), 333-338, 1992.

[36] Z. L. Nikolov and S. L. Woodward, "Downstream processing of recombinant proteins from transgenic feedstock," Current Opinion in Biotechnology, 15(5), 479-486, 2004.

[37] T. Morçöl, Q. He, and S. J. D. Bell, "Model Process for Removal of Caseins from Milk of Transgenic Animals," Biotechnology Progress, 17(3), 577-582, 2001.

[38] A. J. Harvey, G. Speksnijder, L. R. Baugh, J. A. Morris, and R. Ivarie, "Expression of exogenous protein in the egg white of transgenic chickens," Nature Biotechnology, 20(4), 396-399, 2002.

[39] T. S. Park, H. G. Lee, J. K. Moon, H. J. Lee, J. W. Yoon, B. N. Yun et al, "Deposition of bioactive human epidermal growth factor in the egg white of transgenic hens using an oviduct-specific minisynthetic promoter," The FASEB Journal, 29(6), 2386-2396, 2015.

[40] Y. Wang, S. Zhao, L. Bai, J. Fan, and E. Liu, "Expression Systems and Species Used for Transgenic Animal Bioreactors," BioMed Research International, 2013, 2013.

[41] E. Rehbinder, M. Engelhard, K. Hagen, and R. B. Jørgensen, R. Pardo-Avellaneda, A. Schnieke et al, "Promises and risks of biopharmaceuticals derived from genetically modified plants and animals," Berlin: Springer-Verlag Berlin Heidelberg, 2009, p. 26.

[42] M. E. Swanson, M. J. Martin, J. K. O’Donnell, K. Hoover, W. Lago, V. Huntress et al, "Production of functional human hemoglobin in transgenic swine," Biotechnology (N Y), 10(5), 557-559, 1992. 
[43] V. G. Pursel, D. J. Bolt, K. F. Miller, C. A. Pinkert, R. E. Hammer, R. D. Palmiter et al, "Expression and performance in transgenic pigs," Journal of Reproduction and Fertility. Supplement, 40, 235-245, 1990.

[44] D. E. Kerr, F. Liang, K. R. Bondioli, H. Zhao, G. Kreibich, R. J. Wall et al, "The bladder as a biorreactor: Urothelium production and secretion of growth hormone into urine," Nature Biotechnology, 16 (1), 75-79, 1998.

[45] H. M. Zbikowska, N. Soukhareva, R. Behnam, R. Chang, R. Drews, H. Lubon et al, "The use of the uromodulin promoter to target production of recombinant proteins into urine of transgenic animals," Transgenic Research, 11(4), 425-435, 2002.

[46] H. M. Zbikowska, N. Soukhareva, R. Behnam, H. Lubon, D. Hammond, and S. Soukharev, "Uromodulin promoter directs high-level expression of biologically active human $\alpha_{1}$-antitrypsin into mouse urine," Biochemical Journal, 365 (Pt 1), 7-11, 2002.

[47] Z. Y. Ryoo, M. O. Kim, K. E. Kim, Y. Y. Bahk, J. W. Lee, S. H. Park et al, "Expression of recombinant human granulocyte macrophage-colony stimulating factor (hGM-CSF) in mouse urine," Transgenic Research, 10(3), 193-200, 2001.

[48] P. Chrenek, A. V. Makarevich, J. Pivko, and J. Bulla, "Transgenic Farm Animal Production and Application," Slovak Journal of Animal Science, 43(2): 45-49, 2010.

[49] L. R. Bertolini, H. Meade, C. R. Lazzarotto, L. T. Martins, K. C. Tavares, M. Bertolini et al, "The transgenic animal platform for biopharmaceutical production," Transgenic Research, 25(3), 329-343, 2016.

[50] G. Wright, A. Carver, D. Cottom, D. Reeves, A. Scott, P. Simons et al, "High Level Expression of Active Human Alpha-1-Antitrypsin in the Milk of Transgenic Sheep," Biotechnology (N Y), 9(9), 830-834, 1991.

[51] N. Rudolph, "Technologies and economics for protein production in transgenic animal milk", Genetic Engineering News, 17(16), 36-37, 1997.

[52] H. Luboń and R. K. Paleyanda, "Vitamin K-dependent protein production in transgenic animals," Thrombosis and Haemostasis, 78(1), 532-536.

[53] M. Tomita, H. Munetsuna, T. Sato, T. Adachi, R. Hino, M. Hayashi et al, "Transgenic silkworms produce recombinant human type III procollagen in cocoons," Nature Biotechnology, 21(1), 52-56, 2003.

[54] S. Maeda, T. Kawai, M. Obinata, H. Fujiwara, T. Horuchi, Y. Saeki et al, "Production of human alpha-interferon in silkworm using a baculovirus vector," Nature, 315 (6020), 592-594.

[55] M. Markaki, D. Drabek, I. Livadaras, R. K. Craig, F. Grosveld, and C. Savakis, "Stable expression of human growth hormone over 50 generations in transgenic insect larvae," Transgenic Research, 16(1): 99-107, 2007.

[56] W. Gavin, "ATryn®: 1st GE (genetically engineered) animal success story for production of a human recombinant pharmaceutical," BMC Proceedings, 8(Suppl 4), 2014.

[57] A. Sánchez y J. Gadea, "Animales transgénicos para la producción de proteínas humanas," Anales de Veterinaria de Murcia, 30, 7-18, 2014.

[58] M. P. Cruz, "Conestat Alfa (Ruconest): First Recombinant C1 Esterase Inhibitor for the Treatment of Acute Attacks in Patients With Hereditary Angioedema," Pharmacy and Therapeutics, 40(2), 109-114, 2015.

[59] J. Lipozenčić and R. Wolf, "Life-threatening severe allergic reactions: urticaria, angioedema, and anaphylaxis," Clinics in Dermatology, 23(2), 193-205, 2005.

[60] M. Shirley, "Sebelipase Alfa: First Global Approval," Drugs, 75(16), 1935-1940, 2015.

[61] J. A. Bornhorst, F. R. O. Calderon, M. Procter, W. Tang, E. R. Ashwood, and R. Mao, "Genotypes and serum concentrations of human alpha-1-antitrypsin "P" protein variants in a clinical population, Journal of Clinical Pathology, 60(10), 1124-1128, 2007.

[62] D. S. Vinay and B. S. Kwon, "4-1BB (CD137), an inducible costimulatory receptor, as a specific target for cancer therapy," BMB Reports, 47(3), 122-129, 2014.

[63] V. N. Pak, "The use of alpha-fetoprotein for the treatment of autoinmune diseases and cancer," Therapeutic Delivery, 9(1), 37-46, 2018.

[64] N. Raben, P. Plotz, and B. Byrne, "Acid a-Glucosidase Deficiency (Glycogenosis Type II, Pompe Disease)," Current Molecular Medicine, 2(2), 145-166, 2002. 